\title{
Comparing Cannabis Use Disorder in the General Population with Cannabis Treatment Seekers Using Multi-Source National Datasets: Who Receives Treatment?
}

\author{
Deirdre Mongan ${ }^{\mathrm{a}} \quad$ Anne Marie Carew ${ }^{\mathrm{a}} \quad$ Derek O'Neill $^{\mathrm{a}}$ Seán R. Millar ${ }^{\mathrm{a}, \mathrm{b}}$ \\ Suzi Lyons $^{\text {a }}$ Brian Galvin ${ }^{\text {a }}$ Bobby P. Smyth ${ }^{c}$ \\ aHealth Research Board, Dublin, Ireland; 'b School of Public Health, University College Cork, Cork, Ireland; \\ ${ }^{c}$ Department of Public Health \& Primary Care, Trinity College Dublin, Dublin, Ireland
}

\section{Keywords}

Cannabis · Use - Abuse and dependence · Prevalence .

Treatment

\begin{abstract}
Introduction: Given the increased prevalence of cannabis use in Ireland and increase in cannabis potency, this study aimed to estimate the size of the potential population in Ireland that may be in need of cannabis treatment and the percentage of people with cannabis use disorder (CUD) who actually access treatment. We also compared the profile of those with CUD in the general population to those who receive treatment for their cannabis use to explore whether certain subgroups are more or less likely to enter treatment. Method: This was a retrospective, multi-source database study. Data were obtained from (1) Ireland's 2014/2015 national general population survey (GPS) on drug use and (2) treatment data from the Irish National Drug Treatment Reporting System (NDTRS) for 2015. The profiles of GPS cases with CUD and NDTRS cases were compared using 2-sided $t$ tests designed for independent samples. Results: The prevalence of last year cannabis use among adults aged 15 and older was $6.5 \%$ and the prevalence of CUD was $2.6 \%$, repre-
\end{abstract}

karger@karger.com www.karger.com/ear

Karger $\stackrel{\text { ' }}{5}$

GOPEN ACCESS
(C) 2021 The Author(s)

Published by S. Karger AG, Basel

This is an Open Access article licensed under the Creative Commons Attribution-NonCommercial-4.0 International License (CC BY-NC) (http://www.karger.com/Services/OpenAccessLicense), applicable to the online version of the article only. Usage and distribution for commercial purposes requires written permission. senting 94,515 of the Irish population. A total of 4,761 cases entered treatment for problem cannabis use. NDTRS treatment cases were significantly more likely than GPS cases to be unemployed (63.7\% vs. $26.6 \%)$ and have no or primary level only educational attainment (56.3\% vs. $21.2 \%)$. Over half (53.3\%) of NDTRS cases first used cannabis before the age of 15 years, compared to $14.7 \%$ of CUD cases in the population. Discussion/Conclusion: Our findings suggest that earlier users and those with more complex or disadvantaged lives are more likely to seek treatment. A broad population health approach that engages multiple sectors such as health, social welfare, and education is recommended to ensure that there is increased opportunity for people with CUD to be identified and signposted towards treatment.

\section{(C) 2021 The Author(s)}

Published by S. Karger AG, Basel

\section{Introduction}

Cannabis is the most widely used illicit substance in Ireland; in 2014/2015, 8\% of Irish people aged 15-64 years reported last year use of cannabis and $4 \%$ reported last month use [1]. These prevalence figures are considerably higher than for any other illegal drug and have signifi-
Correspondence to:

Deirdre Mongan,dmongan@hrb.ie 
cantly increased since 2002, when the prevalence of last year and last month use was $5 \%$ and $3 \%$, respectively [2]. Among Irish people who have used cannabis within the last year, $20 \%$ are cannabis-dependent. In Ireland, the type of cannabis being used has changed from relatively lowpotency resin ("hash") to high-potency herbal cannabis ("weed") [3]. High-potency cannabis is associated with an increased severity of dependence, especially in young people [4]. The increase in use and move towards higher potency products in Ireland has coincided with a substantial increase in treated cannabis addiction and cannabis-related psychiatric problems [3]. Across Europe, the number of first-time treatment entrants for primary cannabis use has continuously increased from around 43,000 (28\% of all new entrants into drug addiction treatment) in 2006 to around 75,000 (47\% of all new treatment entrants) in 2015 [5]. In Ireland, among first-time treatment entrants, cannabis is the most frequently reported main problem drug, accounting for $38 \%$ of all new entrants [6].

Treatment for substance use in Ireland is delivered using a 4-tier model of care based on the principle of a "continuum of care" that allows the individual to access the supports they require at the level of complexity that reflects their needs and circumstances [7]. Information, advice, and referral interventions are provided through tier 1 of the model. Tier 2 includes early intervention and harm reduction support, which are provided in a community setting and also includes some specialist addiction services. In tier 3, treatment and rehabilitation services provide specialist outpatient interventions in a range of settings usually via a multidisciplinary team, while tier 4 interventions occur in specialised and dedicated inpatient or residential units or wards, which provide detoxification and/or stabilisation treatments and may also include specialised supports for complex needs such as pregnancy and liver- and HIV-related problems [8]. The majority of cases treated for problem drug use in Ireland attend outpatient settings [6].

Those who seek treatment for cannabis use disorder (CUD) are not always representative of those with CUD. A Dutch study comparing cannabis-dependent patients under treatment with non-treatment-seeking cannabisdependent users in the community found that patients under treatment reported more cannabis use, more symptoms of dependence, higher perceived lack of social support, more pressure to seek treatment, a more positive attitude to treatment, and more previous treatments [9]. The US National Survey on Drug Use and Health found that among those with CUD, female, college-educated, or married respondents underutilised cannabis treatment
[10]. Australian research reported that the main barriers to cannabis treatment were treatment not considered necessary to reduce cannabis use, users not being ready to stop using cannabis, a lack of awareness around treatment options, and stigma [11].

Untreated CUD has important public health and social implications. It is associated with cognitive impairment, respiratory disease, increased risk for psychotic disorders and other mental health problems, lower education attainment, and unemployment [12]. There is also the potential for harm to others. Substance use disorders can have adverse impacts on the family, including the children of the person [13]. Given the increased prevalence of cannabis use and the increase in cannabis potency in Ireland, the aim of this study was to estimate the size of the potential population that may be in need of cannabis treatment and to compare the profile of those with CUD in the general population to those who receive treatment for their cannabis use to explore whether certain subgroups in Ireland are more or less likely to enter treatment.

\section{Materials and Methods}

For this retrospective, multi-source database study, data were obtained from 2 sources: (1) Ireland's national general population survey (GPS) on drug use and (2) treatment demand indicator data from the Irish National Drug Treatment Reporting System (NDTRS). As only anonymised data were available, individual data from the different systems could not be linked.

\section{GPS on Drug Use}

To calculate the size of the potential population in Ireland that may need cannabis treatment, we analysed data from the most recent GPS, which was undertaken in 2014/2015. The GPS is undertaken every 4/5 years; it measures the prevalence of drug use and is based on the European Monitoring Centre for Drugs and Drug Addiction's European Model Questionnaire [14]. The survey used stratified, multistage area probability sampling methods to select a representative sample $(n=7,005)$ of the Irish population aged 15 years and older, living in private households. The achieved sample was weighted by gender, age, and former health board region to maximise its representativeness of the general population. The survey excluded people in prison, people classified as homeless, and those living in institutions. Interviews were undertaken face to face in respondent's homes and the survey response rate was $61 \%$. The survey was granted ethical approved by the Royal College of Physicians in Ireland. A more comprehensive description of the survey's methodology is detailed elsewhere [15].

\section{National Drug Treatment Reporting System}

The NDTRS is a national register of addiction treatment in Ireland [16]. The NDTRS is based on the standardised European treatment demand protocol $[17,18]$. Treatment data are provided by statutory and non-statutory services, including outpatient ser- 
vices, residential centres, general practices, and prisons. Service providers collect data including client demographic and socioeconomic information, referral and assessment details, current problem drugs (up to 4 substances), treatment history, injecting risk behaviours, treatment interventions provided, and details of treatment outcome at the time of discharge or transfer to another service. NDTRS data coverage (numbers of admissions and treatment centres reporting data) is high [19]. Data are analysed and reported at national and European levels [20]. The NDTRS records episodes of treatment entry, (cases) as there is currently no national system wide unique identifier in the Irish health system; in any given year, individuals may appear more than once if treated in different centres or if they return to treatment in the same centre. In 2015, 597 treatment services participated in the NDTRS and there were 17,510 episodes of treatment entry, whereby alcohol or drugs were the main problem substance.

To ensure comparability with the GPS, it was important that the NDTRS data mirrored as closely as possible the population of the 2014/2015 GPS. To this end, treated cases deemed unlikely to have been included in the GPS sampling frame at the start of their treatment were excluded. Treatment cases classified as homeless, or who were in prison, or resided outside of Ireland were removed on this basis. Those who lived in residential care or in halfway houses were included, as these are predominantly private dwellings and therefore can potentially be included in the GPS. The study population was all cases who entered cannabis treatment in 2015, who resided in the Republic of Ireland, and lived in private households $(n=4,761)$. Treatment entry cases reporting cannabis as either their main or an additional problem drug were included.

\section{Study Variables}

Cannabis Use Disorder

The fourth edition of the diagnostic and statistical manual of psychiatric disorders (DSM-IV) is published by the American Psychiatric Association and covers all mental health disorders for children and adults [21]. It defines substance abuse and dependence as a maladaptive pattern of substance use leading to clinically significant impairment or distress. In the GPS, cannabis abuse and cannabis dependence were classified according to DSM-IV criteria and were measured via a self-completed questionnaire using 4 items that denote cannabis abuse and 7 items that denote cannabis dependence from the Composite International Diagnostic Interview (CIDI) [22]. The CIDI is a widely accepted and frequently used operationalisation of the DSM-IV. Advised by the European Monitoring Centre for Drugs and Drug Addiction, the abbreviated version, the Munich CIDI, a 19-item instrument reflecting the 4 cannabis abuse and the 7 cannabis dependence criteria, was used [23]. The Munich CIDI has been found to have good reliability and validity among community samples [23,24]. Cannabis abuse was defined as the presence of at least one of the 4 DSM-IV abuse criteria in the 12 months prior to interview. Cannabis dependence was defined as the presence of 3 or more of the 7 DSM-IV dependence criteria in the 12 months before the interview. Cannabis abuse and dependence were considered to be mutually exclusive diagnoses, with those who met the criteria for both abuse and dependence assigned to the dependence group only. CUD was determined as any cannabis abuse or dependence in the 12 months prior to the interview. The potential population in need of cannabis treatment was defined as those who met the criteria for CUD in the general population.

Treatment for Cannabis Use Disorder
Comparison of the Profiles of GPS Respondents and NDTRS Cases

As the NDTRS does not collect information on CUD among cases who present for treatment for cannabis use, we could not directly compare CUD in the general population with CUD in the treatment population. Instead, those who met the criteria for CUD in the GPS were compared with NDTRS cases receiving treatment for cannabis using variables that were common to both datasets. We combined the cannabis abuse and cannabis dependence groups into 1 CUD variable as a comparative analysis indicated no significant differences in sociodemographic or cannabis use variables between the 2 groups (see online suppl. Table 1 ; for all online suppl. material, see www.karger.com/doi/10.1159/000518648). Variables that were common to each dataset were gender, age, education, age of school leaving, employment, region of residence, living with dependent children, and age of first cannabis use. Marital status was recorded in the GPS, while the NDTRS recorded the household composition of cases. To facilitate comparison between datasets, marital status was dichotomised into those who were married or cohabiting and all other marital statuses.

\section{Polydrug Use}

In the GPS, polydrug use was defined as the use of any other illicit drug at any time in the past year. No measures of problematic use were available for other illicit drugs. Respondents were defined as being alcohol dependent if they met DSM-IV criteria for dependence in the past year. In the NDTRS, polydrug users were defined as those who reported problem use of at least one other substance in addition to cannabis, at the start of their treatment episode.

\section{Statistical Analysis}

Population estimates of the prevalence of CUD were reported using 95\% Clopper-Pearson confidence intervals. A combination of descriptive, exploratory statistics, and inferential analysis techniques were used to describe cannabis users' characteristics and their cannabis use. Appropriate measures were reported depending on data distributions; where data were normally distributed, mean scores and standard deviations were reported. Where data were skewed, median and interquartile ranges were reported. The profiles of GPS cases with CUD and NDTRS cases were compared using 2-sided $t$ tests designed for independent samples. Comparisons were undertaken between GPS cases and all NDTRS cases and between GPS cases and NDTRS cases where cannabis was the main problem drug to account for potential differences between NDTRS cases where cannabis was the main problem drug and cases where cannabis was an additional problem drug. GPS data were analysed using Stata SE version 15.1 (Stata Corporation, College Station, TX, USA), while NDTRS data were managed and analysed in the Statistical Package for Social Sciences, version 22.0. For all analyses, a $p$ value ( 2 -tailed) of $<0.05$ was considered to indicate statistical significance.

\section{Results}

Potential Need for the Use of Services to Treat CUD

According to the GPS survey data, 6.5\% (or 241,089) of the general population, aged 15 and older had used 
Table 1. Estimates of past year CUD in the Irish population ( 15 years and over)

\begin{tabular}{lll}
\hline Variable & $\%(95 \% \mathrm{Cl})$ & $\begin{array}{l}\text { Estimate of the Irish population } \\
(95 \% \mathrm{Cl})\end{array}$ \\
\hline Past year use & $6.5(5.8-7.4)$ & $241,089(211,401-270,777)$ \\
CUD & $2.6(2.1-3.1)$ & $94,515(76,249-112,782)$ \\
CUD and other illicit drug use & $1.2(0.9-1.6)$ & $44,333(31,290-57,375)$ \\
CUD and alcohol dependence & $1.0(0.7-1.4)$ & $36,771(24,764-48,779)$ \\
CUD (males) & $4.2(3.3-5.2)$ & $75,882(59,147-92,618)$ \\
CUD (females) & $1.0(0.6-1.5)$ & $18,633(11,203-26,062)$ \\
\hline
\end{tabular}

CUD, cannabis use disorder. cannabis in the previous 12 months. Of those who had used cannabis in the last year, $39.2 \%$ (or 94,515) met the criteria for CUD (Table 1); this included $19.7 \%$ who met the criteria for cannabis abuse and $19.5 \%$ who met the criteria for cannabis dependence. The prevalence of CUD in the general population was $2.6 \%$; this included $1.3 \%$ with cannabis abuse and $1.3 \%$ with cannabis dependence. The prevalence of CUD for males was $4.2 \%$ and $1.0 \%$ for females. NDTRS data reported that 4,761 cases entered treatment for problem cannabis use in 2015. Of these, 2,552 cases had cannabis as a main problem, while 2,209 cases had cannabis as an additional problem. The number of NDTRS treatment cases $(n=4,761)$ represented $2.0 \%$ of the general population who had used cannabis in the last year and $5.0 \%$ of those with CUD.

\section{Profile of Cases Entering Treatment}

The majority of cases who entered treatment were male $(77.5 \%)$ (Table 2$)$. In cases where cannabis was the main problem drug, the age profile was younger, with $36.1 \%$ aged $<20$ years compared to $9.9 \%$ of cases where cannabis was an additional problem drug. The percentage still in education was considerably higher for those where cannabis was the main problem drug (16.6\%) than those for whom cannabis was an additional problem (2.9\%). One half (49.0\%) of all cases had attained primary education only or less. Unemployment was more common among those reporting cannabis as an additional problem drug $(71.8 \%)$ than those reporting cannabis as a main problem drug (53.9\%). Half (51.0\%) of those with cannabis as a main problem drug reported problem use of at least one other substance. The most common additional problem drugs were hypnotics and sedatives, for example, diazepam (36.7\%), cocaine $(30.7 \%)$, and alcohol (29.9\%). For those cases for whom cannabis was an additional problem, opioids such as heroin, methadone, or over the counter/prescription opioids (38.8\%) and alcohol (31.2\%) were the most common main problem drugs.
The median time between referral and treatment start was 7 days. There was no waiting time for $31.0 \%$ of cases who were referred, assessed, and started treatment all on the same day. One half (49.6\%) of cases were self-referrals or referred by family or friends; $17.3 \%$ were referred by social services, $13.0 \%$ were referred by general practitioners or from hospital settings, and $6.9 \%$ were referred by the criminal justice system.

\section{Comparison of Cases with CUD in the Population} with Cases Receiving Treatment for Cannabis Use NDTRS treatment cases were significantly more likely than GPS cases with CUD to be unemployed (63.7\% vs. $26.6 \%)$ and to have completed none or primary level education only ( $56.3 \%$ vs. $21.2 \%$ ) (Table 3 ). GPS cases were significantly more likely to be students ( $25.9 \%$ vs. $13.2 \%)$, but this difference was not observed when compared with NDTRS cases, where cannabis was the main problem drug ( $25.9 \%$ vs. $20.6 \%)$. NDTRS cases were significantly more likely to start using cannabis before the age of 15 years than GPS cases (53.3\% vs. $14.7 \%)$. There were no significant sex differences, with males accounting for approximately 4 in 5 cases in both the GPS and NDTRS. There were no significant differences between GPS and NDTRS cases with respect to age, region of residence, living with dependent children, or polydrug use.

\section{Discussion/Conclusion}

Overview of Results/Comparison with Other Studies The prevalence of last year CUD in the general population in $2014 / 2015$ was $2.6 \%$, which equates to 94,515 of the Irish population. Last year prevalence of cannabis use was similar to the EU average [25]. Few countries have published rates of CUD; however, the Irish rate of CUD is very similar to the US (2.5\%), which was measured using DSM-V [26]. The proportion of last year cannabis us- 
Table 2. Profile of cases seeking treatment for cannabis use

\begin{tabular}{|c|c|c|c|}
\hline Variable & $\begin{array}{l}\text { Cannabis as a } \\
\text { main problem } \\
(N=2,552)(\%)\end{array}$ & $\begin{array}{l}\text { Cannabis as an } \\
\text { additional problem } \\
(N=2,209)(\%)\end{array}$ & $\begin{array}{l}\text { Total } \\
(N=4,761) \\
(\%)\end{array}$ \\
\hline \multicolumn{4}{|l|}{ Sex } \\
\hline Male & 78.9 & 75.9 & 77.5 \\
\hline Female & 20.9 & 23.7 & 22.2 \\
\hline Unknown & 0.2 & 0.4 & 0.3 \\
\hline \multicolumn{4}{|l|}{ Age group, years } \\
\hline Under 20 & 36.1 & 9.9 & 23.9 \\
\hline $20-24$ & 29.4 & 19.4 & 24.8 \\
\hline $25-34$ & 23.3 & 38.8 & 30.5 \\
\hline $35-64$ & 10.6 & 31.4 & 20.2 \\
\hline Over 65 & 0.0 & 0.0 & 0.0 \\
\hline Age not known & 0.6 & 0.4 & 0.5 \\
\hline \multicolumn{4}{|l|}{ Education } \\
\hline Primary/none & 41.3 & 58.0 & 49.0 \\
\hline Completed secondary & 24.8 & 22.0 & 23.5 \\
\hline Completed third level & 3.6 & 5.1 & 4.3 \\
\hline Still in education & 16.6 & 2.9 & 10.2 \\
\hline Not known & 13.8 & 12.0 & 13.0 \\
\hline \multicolumn{4}{|l|}{ Age ceased education } \\
\hline Before 16 years & 21.1 & 36.3 & 28.2 \\
\hline \multicolumn{4}{|l|}{ Employment } \\
\hline Employed & 10.8 & 10.3 & 10.6 \\
\hline Unemployed & 53.9 & 71.8 & 62.1 \\
\hline Student & 20.1 & 4.5 & 12.9 \\
\hline Other & 12.8 & 10.9 & 11.9 \\
\hline Not known & 2.5 & 2.4 & 2.5 \\
\hline \multicolumn{4}{|l|}{ Residence } \\
\hline Stable accommodation* & 91.9 & 89.4 & 90.7 \\
\hline Other unstable accommodation & 2.1 & 2.2 & 2.2 \\
\hline Residential care/halfway house & 4.1 & 5.9 & 4.9 \\
\hline Not known & 1.9 & 2.5 & 2.2 \\
\hline \multicolumn{4}{|l|}{ Living arrangements } \\
\hline Alone & 9.5 & 15.8 & 12.4 \\
\hline Parents and family & 63.9 & 47.6 & 56.3 \\
\hline Alone with child & 3.8 & 4.7 & 4.2 \\
\hline Partner and child & 7.7 & 12.0 & 9.7 \\
\hline With partner & 4.0 & 6.6 & 5.2 \\
\hline Friends & 2.8 & 3.0 & 2.9 \\
\hline Other & 5.5 & 7.6 & 6.5 \\
\hline Foster care & 1.3 & 0.3 & 0.8 \\
\hline Unknown & 1.5 & 2.5 & 2.0 \\
\hline \multicolumn{4}{|l|}{ Dependent children } \\
\hline Living with dependent children & 11.5 & 16.7 & 13.9 \\
\hline \multicolumn{4}{|l|}{ Region } \\
\hline Dublin & 25.4 & 35.9 & 30.3 \\
\hline Rest of Ireland & 74.3 & 63.8 & 69.4 \\
\hline Ireland unknown & 0.4 & 0.2 & 0.3 \\
\hline \multicolumn{4}{|l|}{ Age first cannabis use } \\
\hline Mean (SD) & $14.7(3.2)$ & $15.0(3.9)$ & $14.8(3.6)$ \\
\hline Median (25th, 75th percentile) & $14(13,16)$ & $14(13,16)$ & $14(13,16)$ \\
\hline
\end{tabular}


Table 2 (continued)

\begin{tabular}{|c|c|c|c|}
\hline Variable & $\begin{array}{l}\text { Cannabis as a } \\
\text { main problem } \\
(N=2,552)(\%)\end{array}$ & $\begin{array}{l}\text { Cannabis as an } \\
\text { additional problem } \\
(N=2,209)(\%)\end{array}$ & $\begin{array}{l}\text { Total } \\
(N=4,761) \\
(\%)\end{array}$ \\
\hline \multicolumn{4}{|l|}{ Source of referral } \\
\hline Self & 30.7 & 40.0 & 35.0 \\
\hline Family and friends & 18.0 & 10.6 & 14.6 \\
\hline Other drug treatment centres & 6.2 & 13.2 & 9.5 \\
\hline General practitioner & 5.9 & 5.1 & 5.5 \\
\hline Hospital or other medical source & 8.2 & 6.8 & 7.5 \\
\hline Social services & 20.4 & 13.9 & 17.3 \\
\hline Court/probation/police & 8.8 & 4.8 & 6.9 \\
\hline Other & 0.9 & 4.2 & 2.4 \\
\hline Not known & 0.9 & 1.4 & 1.2 \\
\hline Problem drug use & $\begin{array}{l}\text { Additional } \\
\text { problem drugs } \wedge \\
(n=1,302)\end{array}$ & $\begin{array}{l}\text { Main problem drug, } \\
\text { where cannabis was } \\
\text { an additional problem }\end{array}$ & \\
\hline Alcohol & 29.9 & 31.2 & \\
\hline Cocaine & 30.7 & 12.4 & \\
\hline Hypnotics and sedatives & 36.7 & 14.1 & \\
\hline Opioids & 6.3 & 38.8 & \\
\hline Stimulants & 20.7 & 1.7 & \\
\hline Hallucinogens & 1.8 & 0.1 & \\
\hline Other drugs & 3.9 & 1.7 & \\
\hline Waiting times for treatment & \multicolumn{3}{|c|}{ Median (25th, 75th percentile) } \\
\hline Referral to treatment start, days & $7(0,20)$ & $7(0,21)$ & $7(0,20)$ \\
\hline
\end{tabular}

*Stable refers to the stability of the living situation in 30 days before entering treatment. ${ }^{\wedge}$ Cases where cannabis was the main problem drug. Up to 3 additional problem drugs may be reported.

ers who had CUD was high at 39.2\%. A 2020 meta-analysis found that among people who used cannabis, $22 \%$ had CUD [27]. The number of cases $(n=4,761)$ who received treatment for cannabis represented a very small proportion of Irish people with CUD (5.0\%). The true proportion is likely to be lower as NDTRS cases may represent individuals who have entered treatment more than once for cannabis use in the same calendar year. In Ireland, those with substance use disorder may access inpatient treatment in psychiatric hospitals and these cases are not recorded by the NDTRS. However, the number of such cases in 2015 with a diagnosis of CUD was 242, which only slightly alters the proportion of those with CUD receiving treatment (A. Daly, personal communication April 17, 2020).

Our finding that only a minority of those with CUD seek treatment has been reported previously with respect to cannabis and other substance use $[28,29]$. In the US, survey data indicate that $7.2 \%$ of respondents with past year CUD received cannabis-specific treatment [26]. Recovery from substance use problems without the aid of treatment may also occur. Sareen et al. [30] reported that $55 \%$ of those with never treated substance use disorder at baseline had recovered at a 3-year follow-up without receiving any subsequent treatment. A Dutch study of 207 young adults with cannabis dependence found that $28 \%$ were still dependent at a 3-year follow-up. Of those who were no longer dependent, just 3.6\% had accessed treatment [31]. A relatively high proportion of people do not perceive that they have a substance use problem despite meeting diagnostic criteria [32]. A US study found that only $8.5 \%$ of those with an untreated substance use disorder perceive a need for treatment [33]. Perceiving no need for treatment for cannabis use was cited as the main barrier to treatment in a Spanish study of 16-21 year olds [34]. The definition of treatment can impact on the extent of the "treatment gap," that is, the difference between treatment needs or demand and the numbers in treatment. If engagement with self-help groups or new forms of self-help treatment such as websites or apps to reduce cannabis use are included as forms of treatment, the proportion of untreated people should decrease [35]. As the 
Table 3. Comparison of GPS and NDTRS profiles

\begin{tabular}{|c|c|c|c|c|c|}
\hline Variable & $\begin{array}{l}\text { GPS } \\
(C U D) \\
(N=180)(\%)\end{array}$ & $\begin{array}{l}\text { NDTRS } \\
\text { (all cases) } \\
(N=4,761)(\%)\end{array}$ & $p$ value & $\begin{array}{l}\text { NDTRS } \\
\text { (cannabis main drug) } \\
(N=2,552)(\%)\end{array}$ & $p$ value \\
\hline \multicolumn{6}{|l|}{ Sex } \\
\hline Male & 80.3 & 77.7 & 0.461 & 79.0 & 0.717 \\
\hline \multicolumn{6}{|l|}{ Age, years } \\
\hline$<20$ & 24.4 & 24.1 & 0.964 & 36.3 & 0.108 \\
\hline $20-24$ & 27.3 & 24.9 & 0.704 & 29.6 & 0.737 \\
\hline $25-34$ & 33.7 & 30.7 & 0.619 & 23.5 & 0.076 \\
\hline $35+$ & 14.6 & 20.4 & 0.468 & 10.7 & 0.542 \\
\hline \multicolumn{6}{|l|}{ Region of residence } \\
\hline Dublin & 34.2 & 30.4 & 0.528 & 25.4 & 0.137 \\
\hline \multicolumn{6}{|l|}{ Employment status } \\
\hline Regular employment & 40.9 & 10.9 & $<0.001$ & 11.1 & $<0.001$ \\
\hline Unemployed & 26.6 & 63.7 & $<0.001$ & 55.1 & $<0.001$ \\
\hline Student & 25.9 & 13.2 & 0.016 & 20.6 & 0.394 \\
\hline Other & 6.5 & 12.2 & 0.549 & 13.2 & 0.499 \\
\hline \multicolumn{6}{|l|}{ Marital status } \\
\hline Married/cohabiting & 24.9 & 15.2 & 0.083 & 12.0 & 0.013 \\
\hline \multicolumn{6}{|l|}{ Dependent children } \\
\hline Living with dependent children & 12.9 & 13.9 & 0.891 & 11.5 & 0.840 \\
\hline \multicolumn{6}{|l|}{ Education: highest level completed } \\
\hline Primary/none & 21.2 & 56.3 & $<0.001$ & 47.8 & 0.001 \\
\hline Completed secondary & 15.4 & 27.0 & 0.178 & 28.7 & 0.132 \\
\hline Completed third level & 25.4 & 5.0 & $<0.001$ & 4.2 & $<0.001$ \\
\hline Still in education & 38.1 & 11.8 & $<0.001$ & 19.3 & $<0.001$ \\
\hline \multicolumn{6}{|l|}{ Early school leaver $(<16)$} \\
\hline Yes & 9.8 & 31.8 & 0.046 & 24.0 & 0.163 \\
\hline \multicolumn{6}{|l|}{ Age first used cannabis } \\
\hline Before 15 years & 14.7 & 53.3 & $<0.001$ & 55.0 & $<0.001$ \\
\hline \multicolumn{6}{|l|}{ Polydrug use - alcohol } \\
\hline Yes & 38.9 & 37.5 & 0.814 & 29.9 & 0.116 \\
\hline \multicolumn{6}{|l|}{ Polydrug use - other drugs } \\
\hline Yes & 46.9 & 57.6 & 0.05 & 36.4 & 0.057 \\
\hline
\end{tabular}

All figures are rounded to the nearest decimal place and are based on valid responses. GPS figures are based on weighted data. Significant $p$ highlighted. CUD, cannabis use disorder; GPS, general population survey; NDTRS, National Drug Treatment Reporting System.

NDTRS collects data from treatment services only, it is likely that an unknown number of Irish CUD cases have availed of treatment via their GP, at general counselling services or via self-help groups such as Narcotics Anonymous. The potential size of the population in need of treatment has historically been estimated by measuring the proportion of the people who meet diagnostic criteria in surveys of self-reported symptom such as the CIDI and DSM [36]. This method equates treatment need to prevalence and assumes that substance use diagnosis is a reflection of those who require treatment in the population. There is debate on whether diagnosis of substance use disorder based on DSM criteria indicates a need for treat- ment. It has been argued that simply using such diagnostic instruments is inadequate as they overestimate the total treatment need and do not take into account clinical significance [36-38].

There were no statistically significant sex differences between GPS and NDTRS cases; this is in contrast to the US where women with CUD are significantly less likely than men to receive treatment [10]. Women generally encounter more barriers than men when accessing addiction treatment and are less likely to seek treatment for substance use [39]. It would appear in Ireland that this is not the case for women with CUD. Although women account for a small proportion of CUD cases, they are as 
likely as men to receive treatment. Treated cases were significantly more likely to have commenced cannabis use at an earlier age. Early age of onset of use is a known factor in predicting more severe dependence [27, 40, 41]. Relapse is more common in people who commence use at a young age so they may be over-represented in treatment episodes. Cases receiving treatment for cannabis use were significantly more likely than those in the general population to have lower educational attainment and to be unemployed, which suggests that those with more complex or disadvantaged lives are more likely to seek treatment. This is consistent with the literature, which has found that financial considerations and low educational attainment are associated with treatment entry $[9$, 10]. This finding may be an example of Berkson's paradox [42] where people facing 2 problems, unemployment and CUD, are more likely to appear in clinic-based samples than those with just 1 problem. People from such backgrounds may be more likely to encounter the criminal justice system but such contact is unlikely to explain their increased treatment participation in Ireland as only 6.9\% of case referrals originate from the criminal justice system. It is possible that the negative consequences of cannabis use are greater among those who are socioeconomically disadvantaged. On the other hand, the rate of treatment attendance by people in employment was particularly low. The reasons for this are unclear but warrant exploration. Outpatient-based services tend to operate during standard working hours so this may perhaps be an obstacle for those in employment. There may be additional worries for such people in disclosing to employers their need for time off work to attend addiction treatment. We also found no evidence that parental status was associated with treatment attendance, about 1 in 8 people with a CUD in the population were living with dependent children, a similar proportion as those treated for cannabis use.

Results from the NDTRS indicate that the demand for cannabis treatment in Ireland is being met and met quickly. The median time from referral to treatment start was 7 days, thus, we can conclude that those who want treatment receive it and that long waiting times are not a barrier to accessing treatment. However, our results suggest that there may be a considerable number of people in Ireland with CUD who would benefit from treatment, even if it is more informal treatment types. There is a need to better understand what barriers are preventing people with CUD from accessing help. NDTRS data show that half of all those receiving treatment were self-referrals or referred by family or friends. Just $13 \%$ were referred from health care settings (general practice, acute hospitals, or mental health professionals). This highlights the need for the identification and referral of CUD clients to appropriate treatment services.

\section{Strengths and Limitations}

This study has a number of strengths. To the best of our knowledge, this is the first analysis to comprehensively describe CUD in the general population and the demand for cannabis treatment using multi-source national datasets. The GPS is a large national survey that is representative of the Irish population and used a valid and reliable instrument to measure CUD. The NDTRS is based on a standardised European treatment demand protocol [17], a harmonised methodology for drug treatment data collection, enabling international comparisons. NDTRS data coverage (numbers of admissions and treatment centres reporting data) is high [19] and current drug problems are assessed and recorded by professionals treating the individual with training and documentation on the questionnaire regularly provided. However, this study has a number of limitations which need to be considered when interpreting the findings. The sampling procedures employed by the GPS do not allow for people in prison or other institutionalised individuals, homeless individuals, or travellers (an ethnic minority in Ireland) who do not live in private households, potentially excluding adults with serious cannabis use problems. A total of 232 cases, accounting for $4.6 \%$ of all cannabis treatment cases were excluded on this basis and this limitation was necessary for comparison reasons. It is likely that other measures of disadvantage such as low income, area level deprivation, social isolation, and marginalisation may help explain why treatment entry was so low. However, as these data were not collected in the GPS and NDTRS, such an analysis was not possible. GPS results were based on self-reports that may be influenced by reporting or recall bias. The GPS would be improved by the inclusion of questions on treatment utilisation and on measures of disadvantage to enable more accurate measurement of the extent of treatment seeking or treatment use among the general population. It was not possible to directly compare CUD in the general population with CUD among treated cases, as the NDTRS does not record CUD. It would be of benefit to include CUD scores in the NDTRS to better understand treatment requirements, and, in particular, distinguish between those who seek treatment because of the negative physical or psychological effects of cannabis and those who may be referred through the 
criminal justice system. Also, within the NDTRS it is possible that individuals may appear more than once if they are treated in different centres or if they return to treatment in the same centre within the same calendar year. In the absence of a national system-wide unique identifier in the Irish health system, it is not possible to accurately distinguish between cases and individuals. Therefore, differences between groups may be slightly overestimated as those with complex CUD needs or disadvantaged lives may be more likely to seek treatment more than once per calendar year.

\section{Conclusion}

A considerable number of people in Ireland have CUD, but the overall rate of treatment attendance for cannabis use is low. There is a need to better understand what barriers are preventing people with CUD from accessing help as short waiting times suggest that treatment is available for those who seek it. Given the prominence and availability of cannabis and the likelihood that users tend to be younger and may have limited contact with health professionals, prevention strategies, and early identification of problematic use are recommended. A broader population health approach that engages multiple sectors such as health, social welfare, criminal justice, and education would ensure that there is increased opportunity for people with CUD to be identified and signposted towards treatment.

\section{Statement of Ethics}

Ethical approval for the 2014/2015 GPS was granted by the Royal College of Physicians Ireland (ref: RECSAF 21) and all participants gave written informed consent. The analyses using the NDTRS presented in this paper used routinely collected and anonymised secondary data; study-specific consent was therefore not required.

\section{Conflict of Interest Statement}

The authors have no competing interests to declare.

\section{Funding Sources}

Funding for the NDTRS and 2014/2015 GPS was provided by the Department of Health, Ireland. The funder had no role in the analysis, decision to publish, or preparation of the manuscript.

\section{Author Contributions}

D.M., A.M.C., and B.P.S. contributed to the study conception and design; D.M., A.M.C., D.O.N., and S.R.M. contributed to analysis and interpretation of data; D.M., A.M.C., and D.O.N. drafted the manuscript; S.L., B.G., and B.P.S. contributed to the critical revision. All authors reviewed and approved the final version of the manuscript.

\section{Data Availability Statement}

The datasets used and/or analysed during the current study are available from the corresponding author upon reasonable request.

\section{References}

1 National Advisory Committee on Drugs and Alcohol NIDoH. Prevalence of drug use and gambling in Ireland \& drug use in Northern Ireland. Bulletin 1. Dublin: National Advisory Committee on Drugs and Alcohol; 2016.

2 National Advisory Committee on Drugs (NACD) \& Drug and Alcohol Information and Research Unit (DAIRU). Drug use in Ireland \& Northern Ireland: first results (revised) from the 2002/2003 drug prevalence survey. Dublin: National Advisory Committee on Drugs; 2005.

3 Smyth BP, O'Farrell A, Daly A. Cannabis use and associated health problems: what's the harm? Ir Med J. 2019 Oct 15;112(9):1000.

4 Freeman TP, Winstock AR. Examining the profile of high-potency cannabis and its association with severity of cannabis dependence. Psychol Med. 2015 Nov;45(15):31819.

Treatment for Cannabis Use Disorder
5 Montanari L, Guarita B, Mounteney J, Zipfel N, Simon R. Cannabis use among people entering drug treatment in Europe: a growing phenomenon? Eur Addict Res. 2017;23(3): 113-21.

6 O’Neill D, Carew A, Lyons S. Drug treatment in Ireland 2013 to 2019. Dublin: Health Research Board; 2020.

7 Bryant-Jefferies R. Models of care for drug service provision. Oxford: Radcliffe Publishing Ltd; 2004.

8 Department of Health. Reducing harm, supporting recovery. A health-led response to drug and alcohol use in Ireland 2017-2025. Dublin: Department of Health; 2017.

9 van der Pol P, Liebregts N, de Graaf R, Korf DJ, van den Brink W, van Laar M. Facilitators and barriers in treatment seeking for cannabis dependence. Drug Alcohol Depend. 2013 Dec 1;133(2):776-80.
$10 \mathrm{Wu}$ LT, Zhu H, Mannelli P, Swartz MS. Prevalence and correlates of treatment utilization among adults with cannabis use disorder in the United States. Drug Alcohol Depend. 2017 Aug 1;177:153-62.

11 Gates P, Copeland J, Swift W, Martin G. Barriers and facilitators to cannabis treatment. Drug Alcohol Rev. 2012 May;31(3):311-9.

12 Volkow ND, Baler RD, Compton WM, Weiss SR. Adverse health effects of marijuana use. N Engl J Med. 2014 Jun 5;370(23):2219-27.

13 Madras BK, Han B, Compton WM, Jones CM, Lopez EI, McCance-Katz EF. Associations of parental marijuana use with offspring marijuana, tobacco, and alcohol use and opioid misuse. JAMA Netw Open. 2019;2(11):e1916015.

14 European Monitoring Centre for Drugs and Drug Addiction. Handbook for surveys on drug use among the general population. Lisbon: EMCDDA; 2002. 
15 Ipsos MRBI. General population survey on drug prevalence in Ireland 2014/15. Technical report. Dublin: National Advisory Committee on Drugs and Alcohol; 2016.

16 Carew AM, Comiskey C. Rising incidence of ageing opioid users within the EU wide treatment demand indicator; the Irish opioid epidemic from 1996 to 2014. Drug Alcohol Depend. 2018 Nov 1;192:329-37.

17 European Monitoring Centre for Drugs and Drug Addiction. Treatment demand indicator (TDI) standard protocol 3.0. Guidelines for reporting data on people entering drug treatment in European countries. Luxembourg: Publications Office of the European Union; 2019.

18 Montanari L, Pirona A, Guarita B, Hedrich D, Mounteney J, Vicente J. The experience of the treatment demand indicator in Europe: a common monitoring tool across 30 countries. J Stud Alcohol Drugs Suppl. 2019 Jan;Sup 18: 139-51.

19 Health Research Board. Irish National Focal Point to the European Monitoring Centre for Drugs and Drug Addiction. Focal point Ireland: national report for 2016. Dublin: Health Research Board; 2017.

20 Carew AM, Cafferty S, Long J, Bellerose D, Lyons S. Travellers accessing addiction services in Ireland (2007 to 2010): analysis of routine surveillance data. J Ethn Subst Abuse. 2013;12(4):339-55.

21 American Psychiatric Association. Diagnostic and statistical manual of mental disorders. 4th ed. Washington, DC: American Psychiatric Association; 1994.

22 Kessler RC, Ustün TB. The World Mental Health (WMH) survey initiative version of the World Health Organization (WHO) composite international diagnostic interview (CIDI). Int J Methods Psychiatr Res. 2004; 13(2):93-121.

23 Lachner G, Wittchen HU, Perkonigg A, Holly A, Schuster P, Wunderlich U, et al. Structure, content and reliability of the Munich-composite international diagnostic interview (MCIDI) substance use sections. Eur Addict Res. 1998 Mar;4(1-2):28-41.
24 Wittchen HU, Lachner G, Wunderlich U, Pfister H. Test-retest reliability of the computerized DSM-IV version of the Munichcomposite international diagnostic interview (M-CIDI). Soc Psychiatry Psychiatr Epidemiol. 1998 Nov;33(11):568-78.

25 European Monitoring Centre for Drugs and Drug Addiction. European drug report 2019: trends and developments. Luxembourg: Publications Office of the European Union; 2019.

26 Hasin DS, Kerridge BT, Saha TD, Huang B, Pickering R, Smith SM, et al. Prevalence and correlates of DSM- 5 cannabis use disorder, 2012-2013: findings from the national epidemiologic survey on alcohol and related conditions-III. Am J Psychiatry. 2016 Jun 1;173(6): 588-99.

27 Leung J, Chan GCK, Hides L, Hall WD. What is the prevalence and risk of cannabis use disorders among people who use cannabis? A systematic review and meta-analysis. Addict Behav. 2020 Oct; 109:106479.

28 Babor TF, Stenius K, Romelsjo A. Alcohol and drug treatment systems in public health perspective: mediators and moderators of population effects. Int J Methods Psychiatr Res. 2008 Jun;17(Suppl 1):S50-9.

29 Rush B. Tiered frameworks for planning substance use service delivery systems: origins and key principles. Nord Stud Alcohol Drugs. 2010;27(6):617-36.

30 Sareen J, Henriksen CA, Stein MB, Afifi TO, Lix LM, Enns MW. Common mental disorder diagnosis and need for treatment are not the same: findings from a population-based longitudinal survey. Psychol Med. 2013 Sep; 43(9):1941-51.

31 van der Pol P, Liebregts N, de Graaf R, Korf DJ, van den Brink W, van Laar M. Three-year course of cannabis dependence and prediction of persistence. Eur Addict Res. 2015; 21(6):279-90.

32 Probst C, Manthey J, Martinez A, Rehm J. Alcohol use disorder severity and reported reasons not to seek treatment: a cross-sectional study in European primary care practices. Substance abuse treatment, prevention, and policy. Subst Abuse Treat Prev Policy. 2015 Aug 12;10:32.
33 Mojtabai R, Crum RM. Perceived unmet need for alcohol and drug use treatments and future use of services: results from a longitudinal study. Drug Alcohol Depend. 2013 Jan 1; 127(1-3):59-64.

34 Fernández-Artamendi S, Fernández-Hermida JR, García-Fernández G, Secades-Villa R, García-Rodríguez O. Motivation for change and barriers to treatment among young cannabis users. Eur Addict Res. 2013;19(1):2941.

35 Ritter A, Mellor R, Chalmers J, Sunderland M, Lancaster K. Key considerations in planning for substance use treatment: estimating treatment need and demand. J Stud Alcohol Drugs Suppl. 2019 Jan;Sup 18:22-30.

36 Tremblay J, Bertrand K, Blanchette-Martin N, Rush B, Savard AC, L'Espérance N, et al. Estimation of needs for addiction services: a youth model. J Stud Alcohol Drugs Suppl. 2019 Jan;Sup 18:64-75.

37 Babor TF, Rush B, Tremblay J. Needs-based planning for substance use treatment systems: progress, prospects, and the search for a new perspective. J Stud Alcohol Drugs Suppl. 2019 Jan;Sup 18:154-60.

38 Ritter A, Chalmers J, Gomez M. Measuring unmet demand for alcohol and other drug treatment: the application of an Australian population-based planning model. J Stud Alcohol Drugs Suppl. 2019 Jan;Sup 18:42-50.

39 Green CA. Gender and use of substance abuse treatment services. Alcohol Res Health. 2006; 29(1):55-62.

40 Behrendt $\mathrm{S}$. The role of age in the onset and further development of cannabis use disorders. In: Preedy V, editor. Handbook of cannabis and related pathologies: biology, pharmacology, diagnosis, and treatment. Academic Press; 2017. p. 138-50.

41 Kelly A, Weier M, Hall W. The age of onset of substance use disorders. In: de Girolamo G, McGorry P, Sartorius N, editors. Age of onset of mental disorders. Cham: Springer; 2019.

42 Berkson J. Limitations of the application of fourfold table analysis to hospital data. Int $J$ Epidemiol. 2014 Apr;43(2):511-5. 